University of Washington Tacoma

UW Tacoma Digital Commons

$9-4-2020$

\title{
Measuring Our Success in Teaching Latinos about Asthma and Home Environments: Lessons Learned from an Intervention Developed through Photovoice
}

\author{
Robin Evans-Agnew \\ University of Washington Tacoma, robagnew@uw.edu \\ Alejandra Trujillo \\ Maria Tinajera \\ Silvia Alonso \\ Julie Marie Postma \\ Washington State University
}

Follow this and additional works at: https://digitalcommons.tacoma.uw.edu/nursing_pub

\section{Recommended Citation}

Trujillo, A., Evans-Agnew, R., Tinajera, M., Alonso, S., \& Postma, J. M. (2020). Measuring Our Success in Teaching Latinos about Asthma and Home Environments: Lessons Learned from an Intervention Developed through Photovoice. Progress in Community Health Partnerships: Research, Education, and Action, 14(3), 381-392. https://doi.org/10.1353/cpr.2020.0043

This Article is brought to you for free and open access by the Nursing \& Healthcare Leadership at UW Tacoma Digital Commons. It has been accepted for inclusion in Nursing \& Healthcare Leadership Publications by an authorized administrator of UW Tacoma Digital Commons. 
Title: Consejos ambientales: An educational intervention for Latino parents to improve indoor air quality and asthma

Abstract (199 words)

Maintext (3997k)

Alejandra Trujillo

Robin A. Evans-Agnew, PhD, RN (Corresponding)

Associate Professor

Nursing and Healthcare Leadership

University of Washington Tacoma

Julie Postma, PhD, RN

Associate Professor

Washington State University College of Nursing

WSU Puyallup Research and Extension Center

Maria Tinajera

Silvia Alonso

Acknowledgements: We wish to acknowledge the contributions made by other members of the Mujeres Latinas Apoyando la Comunidad including Gabriela Avendano, Dulce Chávez, Yuribeth Cortes, Antonia Dolores Cortez, Belen Molina, Verónica Gonzales, Araceli Martínez, Sandra Cuin Martínez, and Maria Saravia. We thank other members of the research support team, including Ariana Ochoa Camacho (Latinx studies Professor), Judy Olsen (Environmental health specialist), Stephen Reville (Pediatrician), David Ricker (Pediatrician), and Milagro Thompson (Cultural Liaison). Others provided essential supports for this project including Faaulina Pritchard and the Asia Pacifc Cultural Center (Meeting space); Julio Quan (Mentoring); Maralise Hood-Quan, Center for Conflict and Resolution (Group organizing skills); and Paul Lovelady and Mark Depaul (Multimedia production). We are grateful to the Puget Sound Asthma Coalition for their support and encouragement and to Lee Sledd and Tacoma Community College English Language Learners Program. 
Caring for a child with asthma is an environmental justice concern for Latino immigrant parents. ${ }^{1}$ Asthma affects 7.1 million United States (US) children aged 0-17 years and disproportionately affects racial and ethnic minorities and those with family incomes below the poverty level. ${ }^{2}$ Early childhood is a period of greatest epigenetic risk from exposure to environmental toxins. ${ }^{3}$ Latino children (including those of Mexican descent) have similar prevalence of asthma compared to non-Hispanic White children but have poorer control and higher rates of emergency room admissions. ${ }^{4,5}$ Evidence suggests that asthma is under-diagnosed among Mexican-Americans. ${ }^{6}$

Latino children with asthma face many barriers, often leading to inadequate diagnosis and treatment of the disease. ${ }^{7,8}$ Environmental factors, poverty, and language barriers are some of the systematic oppressions faced by immigrant families with asthma. ${ }^{8-10}$ Researchers have reported on educational needs for Latinos, including safer cleaning products and better ventilation. ${ }^{11-13}$ Latino parents have expressed their frustration at how little control they have over their home environments in rented accommodations ${ }^{14}$ and over the inadequacy of translated materials. ${ }^{15}$

We are a team of Mexican-American mothers of children with asthma partnered with public health experts and nurse researchers from two universities in Washington state. We have observed that indoor air pollution is an important environmental threat for local Mexican immigrant communities. Some of us grew up in hotter environments where the common practice in homes was to leave the windows and doors open to increase ventilation. In Washington this is often not possible. Cleaning chemicals may also negatively influence indoor environments in our homes. Almost $75 \%$ of household cleaning products might be detrimental to lung health ${ }^{16}$, but as one of our team members stated: "[In the USA] more chemicals are within our budget and we let ourselves be influenced by the commercials of how these products can be made to work and we never look at the health consequences for our children."

Research approaches that involve Latino community members in the research process increase the value of research and expedite translation of research findings into practice. ${ }^{17-19}$ Our partnership has developed over five years. Beginning in 2014, we began to partner with researchers and pediatricians from an asthma coalition to investigate the 
challenges our families have with asthma management. ${ }^{20-22}$ Together, we used photovoice to share our stories, experiences, and ideas for action and advocacy. ${ }^{23}$ In our first project, we prioritized environmental threats to our children with asthma, ${ }^{24}$ and discovered new strengths within ourselves for educating and helping others in our community. ${ }^{21}$ In our second project, we formed a community-based participatory research (CBPR) group with the same research team and named ourselves the "Mujeres Latinas Apoyando la Comunidad" (Latinas helping the community - MLAC). CBPR is guided by a set of principles aimed at community engagement and partnership to address community concerns. ${ }^{25} \mathrm{We}$ used our cameras to document and write about environmental risks in child-care environments via "phototexts" (e.g. captions). These photovoice activities helped us to design, pilot-test, and publish a walk-through tool for assessing risks in childcare environments. ${ }^{22}$ The photovoice method has been a foundation for our practice and educational outreach to others. As a group we have collected a catalog of images that we use to authentically inform and teach others about our experience of our children's asthma.

The third study we conducted is described in this article. We received funding $(\$ 20 \mathrm{~K})$ to design and pilot-test a culturally-appropriate, group education intervention to teach Latino parents to identify and mitigate indoor environmental threats for asthma. We agreed that group education using our photovoice archive would help us share our stories motivating changes in social norms around home care through talking about photographs through phototexts. ${ }^{26-28}$ This approach is consistent with social cognitive theory, where the interaction between the social environment (e.g. social support) and personal factors, such as levels of understanding and the confidence to take action (e.g. self-efficacy), are instrumental to behavior change. ${ }^{29}$ Groups generate more opinions and we wanted to support and learn from one another. Latino families may identify more with educators of their own ethnicity and nationality because they may be more confident in discussing the care of their children with others who speak in their own language. In this article we describe the lessons we learned from a group educational program that we designed, implemented, and evaluated for immigrant (Spanish-speaking) Latino populations on reducing the threats to asthma from indoor air pollution.

\section{Methods}




\section{Partner Roles}

This was a CBPR project led by the women, with support from a bilingual cultural liaison, an interpreter, and a research support team (RST) comprised of public health practitioners, clinicians, health science students, and nursing researchers. The cultural liaison had a background as a community health worker conducting asthma home visits. She helped coordinate and facilitate meetings, and kept the group connected and focused.

We developed a 60-minute group educational program based on Spanishlanguage educational materials on asthma and indoor air quality from local government and clinic sources. ${ }^{30-32}$ We agreed to develop our lesson plan around a culturally appropriate practice known in Mexico as demostración (discussion) circles. MLAC peer educators used framed photographs and phototexts they made or retrieved from their photovoice archive to facilitate instruction. ${ }^{21,22,24}$ The interpreter provided simultaneous interpretation during meetings and translated our materials and study tools.

We divided ourselves into four work teams to accomplish the work of the project including: 1) Group education design, 2) Writing, 3) Leadership and training, and 4) Membership (Table 1). All the Mexican-American mothers in our team participated as peer educators in the intervention. Some of the women in the writing team chose to become the authors of this article in partnership with two of the nurse researchers. All of the authors of this article were involved with/in describing the problem, analyzing data, determining and discussing our findings, deciding on implications, and reviewing revisions of the manuscript.

Place Table 1 here

The RST provided technical support for grant writing, recruiting, and providing content for the women to review for inclusion in the training. They coordinated the development of the intervention, provided supports for strengthening the partnership, and designed the data collection tools with input from the women. MultiCare Health System's Institutional Review Board approved this study. Upon joining, MLAC members were required to complete the National Institutes of Health-approved "Project TRES," or 
Training in Ethics and Research Standards as agreed upon by the MultiCare Health System's Institutional Review Board. ${ }^{33}$ The grant provided reimbursement (\$50/month) for the Mexican-American women members, plus funds for the cultural liaison and the interpreter (Figure 1). None of the other partners in the RST received compensation.

Insert Figure 1 here.

\section{Research Design and Intervention}

We evaluated our intervention with a one-group, pre- and post-test design ${ }^{34}$ to measure our successes in teaching other Latinos about asthma and home environments. We hypothesized that participants would adopt new behaviors in the demostración circles by observing the actions of their peers (as demonstrated in their photos) and feeling social support in a safe space. Participants would develop self-efficacy by sharing opinions and experiences with each other. ${ }^{29}$ Class topics included how to: 1) control mold and kill dust mites by washing the sheets and stuffed animals; 2) clean with non-toxic vinegar and baking soda; 3) reduce contaminants in our homes through shoe removal and ventilation; and 4) select filters and vacuums.

\section{Measures}

We evaluated changes in participant knowledge about home environmental triggers and self-efficacy for removing these triggers. Identical pre- and post-data collection surveys included five multiple-choice questions on asthma, mold, bleach, home triggers, and dust mites. We utilized existing questions from validated surveys for three of these questions ${ }^{35,36}$ and developed the remaining two in Spanish to match the class topics. We included two self-efficacy questions reflecting confidence in reducing triggers in the home and confidence in taking steps to reduce children's exposure to tobacco smoke. We included five short answer prompts for participants to evaluate the class (e.g. "Was this class interesting? Why or why not?"). We also collected demographic information and made field notes using a structured observation guide.

\section{Recruitment and Sample}

We obtained a convenience sample of adult students participating in an English language literacy class of which several of our team were alumni. We received 
permission from the program director whose staff had collaborated with us on our first photovoice project. ${ }^{20}$ We then implemented our educational intervention during a twohour evening class. Participants identified as Latino/Hispanic parents whose first language was Spanish.

\section{Data Collection, Procedures, and Analysis}

Mexican women members of MLAC welcomed participants as they entered the classroom, inviting them to help themselves to a light snack and their children to play games in an adjoining room. Once people were settled, the women stood in front of the group and gave a formal welcome in Spanish. They introduced the photovoice work of MLAC and explained why asthma and asthma prevention is important. They explained our research to the group and read aloud an informed consent. All class members voiced their agreement to participate. Our interpreter provided English interpretation for the benefit of the non-bilingual (RST) team members.

We collected a pre-test immediately before our class started. When participants were finished they were invited to join the women from our team who had chosen to be women-educators at one of the four discussion circles in the classroom. They passed photographs they had taken from prior photovoice studies around the table and told stories about them related to the topic to stimulate discussion. They discussed their experiences caring for their own children with asthma. Some of the women-educators included physical demonstrations (e.g. changing a vacuum bag). They answered all participants' questions. After about fifteen minutes, the women-educators rotated to a different table of participants.

The post-test was collected immediately following the class. We ended by handing out "green cleaning kits" that contained vinegar, a spray bottle, baking soda, chlorine-free powdered cleanser, microfiber cloths, and kitchen gloves. To assist with our debrief of the event, we invited a graduate student from one of the partner universities with make detailed observation notes of the process and any challenges observed.

One week later we debriefed about the event. Each team member wrote and discussed their observations. We used our own recollections and the notes made by the observer to discuss the process of the training and anything else we had observed concerning challenges participants experienced. Changes in knowledge and self-efficacy 
were summarized using descriptive statistics. Participants' text responses to the class evaluation were summarized per question.

\section{Results}

Nineteen Spanish-speaking participants from Mexico (74\%) and Central or South America (26\%) attended the educational workshop (Table 2). The participants were mainly between 30 and 40 years of age (84\%) and had lived in the US for more than 10 years $(84 \%)$. Most were caring for between 3-4 children in their home (53\%), and some (26\%) utilized childcare. Some participants reported having children with allergies (15\%) or asthma $(11 \%)$.

Insert Table 2 here

All 19 participants completed the pre- and post-knowledge survey (Table 3). Baseline knowledge varied from $0 \%$ (what happens to the lungs) to $95 \%$ (bleach safety). Improvement was seen in two of the five knowledge questions: what happens to the lungs during an asthma attack ( $0 \%$ pre- to $24 \%$ post) and ways to control dust mites ( $35 \%$ preto $44 \%$ post). A decrease in scores was seen in knowledge questions related to actions that encourage mold growth (53\% pre- to $31 \%$ post) and things that make asthma worse in the home (61\% pre- to $47 \%$ post).

Insert Table 3 here

Participants completed the pre- $(n=18)$ and post- $(n=16)$ surveys on confidence for mitigating triggers in the home; 17 completed both pre- and post-test for efficacy on reducing tobacco (Figures 2 and 3). Participant confidence in mitigating home environmental triggers was high at baseline. Self-efficacy (confidence) scores increased in both measures on post-test.

Insert figure 2 here

Insert figure 3 here 
All participants completed the open-ended evaluation questions. Participants wrote that the class was interesting because the women-educators kept their attention and expanded their thinking. Some liked the organization and the use of photographs to help explain things correctly. For example, one participant wrote that they liked the “Organización, información, fotos, información breve pero concreta/organization, information, photos, and brief but relevant information." They were concerned about the effects of cleaning products on children's health. Participants recommended deeper explanations using photos. For example, "Como mas foto de lo que habla/More photos from which to learn."

At our debrief meeting, we discussed how helpful the photographs were and noted that participants used their cell phones to take photos of the photographs. We discussed how we might better educate others in the future. For example, some participants appeared nervous taking the surveys. We also discussed the implications of this project. One member of our group summarized saying, "It is our mission [as MLAC members] to take care of the environment in order to have a better health and a better life, not only humans but also all living beings."

\section{Discussion}

This research was conducted in a real world setting by a team with few resources for extensive recruitment. It was logical for us to partner with the English literacy program that some of us were the alumni of. The prevalence of asthma in this sample (10\%) aligns with the expected statewide asthma among Latino populations. ${ }^{37}$ Participant demographics are representative of Latino immigrants in the western US, in terms of origin, education, and family structure. ${ }^{38-40}$

Our evaluation produced mixed results. In response to the open-ended questions, participants wrote that they had learned new things and they appreciated the demostración design and the use of photos. Consistent with social cognitive theory, selfefficacy increased for mitigating home environments and tobacco exposures. However, participant knowledge on controlling mold and indoor triggers declined (Table 3). The next section discusses these mixed results and outlines lessons learned and 
recommendations for low-resourced CBPR involving partner development, implementation, and evaluation of an educational intervention.

\section{Lessons Learned}

This is the first time CBPR and photovoice have been combined to develop a home-related environmental education program for Latino communities. Partners were satisfied with the demostración design and the preparation through monthly meetings and work teams. CBPR is time-consuming but maximizes reflection and investigation of a problem with co-researchers who have similar cultural experiences as study participants. ${ }^{25} \mathrm{We}$ found that efficacy for reducing triggers can be improved through culturally-tailoring an educational intervention that includes peer education in discussion circles using photographs and phototexts. Our photographs and phototexts developed through prior photovoice activities were a relevant way to provide step-by-step advice for other parents, while keeping in mind their own experiences in their own homes.

Ideally, we would have devoted more resources and time to building our skills in evaluation design. This is similar to problems others have also described in instrument development, translation, and data collection. ${ }^{41-43}$ The RST were primarily responsible for compiling the pre- and post-test. Our Mexican-American team members developed two knowledge-survey questions in Spanish (Table 3) and completion rates were the same across all the questions. While an earlier draft of the knowledge survey did feature graphics, the final five-question survey was multiple-choice. We used printed surveys completed by the participants rather than oral surveys. Our peer educators refined their message up to the point of implementation making it harder to select appropriate questions that would align to the content of each demostración circle. In the following section, we discuss our lessons learned and recommendations for future instrument development, translation, and data collection below.

Instrument development. Researchers have described the process of developing and testing instruments as an "intricate dance" 43 between academic and community members requiring time, facilitation, and training. The RST surveyed and selected existing questions and identified gaps; and the Mexican-American women on our team 
provided input into question structure (Table 4). Our RST did not find psychometricallyvalidated knowledge tests specific to reducing environmental triggers for asthma in Spanish or English; however, they did find previously used questions in English and Spanish that were discriminatory enough to detect an improvement after a similar intervention. ${ }^{36}$ Therefore we selected three existing questions and designed two others.

We only reviewed the survey questions once about a month prior to implementation. Building time to iteratively develop questions and evaluate them with community partners is critical. In retrospect we would recommend having a special team first think about the way to collect the data, such as through an interview with each participant, and then ask ourselves what content we should be evaluating. In our case, instrument development was second in priority to developing the educational session.

Given that participants responded well to the use of photographs, we recommend that these images be used in the evaluation. For example, participants could have been asked to identify environmental threats within an image. Ideally, pre-testing the questionnaires should be completed with a small sample of the community of focus to obtain feedback on the usability of the test questions and the understandability of the entire intervention. Participant responses from this testing phase should then be discussed and incorporated as appropriate into the actual intervention.

Other computer-assisted methods for taking surveys exist, but were beyond our budget. ${ }^{45}$ However, because the use of photos was so positively received, we suggest archived photographs and phototexts, collected by a CBPR team through photovoice can be an important modality for cross-cultural communication. In the future we intend to embed our photographs and phototexts within the evaluation process.

Insert Table 4 here

Instrument translation. Other researchers have described time-intensive processes for instrument translation involving significant community input ${ }^{42}$ and a focus on conceptual, not semantic, relevance of the translation (Table 4). In using previously developed questions, we missed common pitfalls associated with asking multiple-choice 
questions such as using the word "except" and double negatives. ${ }^{44}$ This is especially important among people who are not used to taking multiple-choice tests.

We also found that there were differences in conceptual understandings of the survey between our interpreter, who was from Mexico City, and most of the peer educators, who were from southern Mexico. Notably, our sample population was from four Spanish-speaking countries. No relevant instruments that our study team is aware of have been psychometrically tested among such a heterogeneous Latino population. We recommend building time into the planning process for partner critique of the translated survey, and to involve more than one interpreter.

Data collection and management. Time was short in the session to collect the surveys. Participants were confused by the questions and needed assistance to complete them. Others have described the considerable resources needed to improve data collection and management in CBPR settings including the training of peer educators to assure fidelity (Table 4). ${ }^{41}$ While our team members were satisfied with the Project TRES human subjects training, this training did not extend to skills in data collection and management. We recommend training for CBPR teams in data collection; planning time for data collection and debriefing; and, for small projects, planning for one-on-one support for survey completion, especially in groups with low-literacy.

\section{Limitations}

This was a small research study evaluating a culturally-tailored educational intervention based on our experiences as Latinas from Mexico. While we found the demostración style program to be appropriate for our participants who had backgrounds in Central and South American countries, this program may not be appropriate for all Latino populations. We were not able to direct our intervention solely towards Latino parents of children with asthma. We do not know whether the changes we saw in our participants after one class will be sustained.

\section{Sharing the results with the community}


In addition to presenting our findings to the healthcare system funder and area clinicians, the we produced a series of short, instructional YouTube videos based on our photographs, phototexts, and the women-educators' presentations to participants. ${ }^{46}$ These have been shared with school nurses and a promotora program at a federally qualified health center. Working from a Spanish transcription of the videos, we also developed an informational booklet for parents and handed these out at two community festivals. Since this study, we have helped adapt and test a "Self-Efficacy in Environmental Risk Reduction" instrument to Spanish-speaking audiences. ${ }^{47}$

\section{Implications}

Community health worker education in the home of families about environmental triggers for asthma is an evidence-based practice. ${ }^{48}$ Our study shows potential for translating this practice into a group educational session, especially for Spanish-speaking US immigrants from Central and South America. Group education sessions are reimbursable for Medicaid populations who have asthma. ${ }^{49}$ Facilitating small, interactive groups and teaching them about environmental triggers would be a novel, reimbursable, and culturally appropriate expansion of the community health worker role. Healthcare systems should devote more resources to develop group education programs that are linguistically and culturally-tailored to the populations they serve. For clinicians and healthcare systems, the mitigation of home environmental triggers for asthma are one component of the guidelines for asthma control that may decrease health disparities and reduce the epigenetic risk for asthma in low-income and minority populations. ${ }^{50-53}$

Our demostración style of peer-education using photographs is a novel strategy that could be scaled up. Using visual materials to provide concrete examples for health education have been recommended for Latino communities ${ }^{54}$, but this is the first time that photovoice methods have been employed to achieve this. Using the photovoice method

and archiving our photos for empowerment education is unique. We only found one study on the re-use of photovoice archive material from South Africa, where community health workers re-interpreted images taken by youth on the topic of HIV. ${ }^{55}$ In our study, our prior photovoice investigations enriched our educational design. Based on the warm 
reception by participants, we believe that photovoice can also be an innovative way to develop evaluation survey tools.

\section{Conclusion}

We described lessons learned from a CBPR study involving Mexican-American researchers who are mothers of children with asthma. In collaboration with the RST, MLAC writing team members conceived, designed, implemented, analyzed, and wrote this article including the results and discussion sections. CBPR designs have the potential for high impact in the cultural-tailoring of educational interventions for immigrant Spanish-speaking parents on indoor environmental threats for asthma. We offer recommendations for low-resourced CBPR studies involving instrument development, translation, and data collection. Cultural tailoring of educational materials using photographs developed in photovoice is a feasible method. Through this partnership project we empowered ourselves and other immigrant communities to take steps to reduce and eliminate indoor environmental threats to our children. 


\section{References}

1. Minkler M, Garcia AP, Williams J, LoPresti T, Lilly J. Si se puede: using participatory research to promote environmental justice in a Latino community in San Diego, California. J Urban Health. 2010;87(5):796-812. Epub 2010/08/05. doi: 10.1007/s11524-010-9490-0. PubMed PMID: 20683782; PubMed Central PMCID: PMCPmc2937121.

2. Akinbami LJ, Sullivan SD, Campbell JD, Grundmeier RW, Hartert TV, Lee TA, et al. Asthma outcomes: healthcare utilization and costs. J Allergy Clin Immunol. 2012;129(3 Suppl):S49-64. Epub 2012/03/14. doi: 10.1016/j.jaci.2011.12.984. PubMed PMID: 22386509.

3. Martinez FD, Vercelli D. Asthma. Lancet. 2013;382(9901):1360-72. Epub 2013/09/18. doi: 10.1016/s0140-6736(13)61536-6. PubMed PMID: 24041942.

4. Oraka E, Iqbal S, Flanders WD, Brinker K, Garbe P. Racial and ethnic disparities in current asthma and emergency department visits: findings from the National Health Interview Survey, 2001-2010. J Asthma. 2013;50(5):488-96. Epub 2013/04/03. doi: 10.3109/02770903.2013.790417. PubMed PMID: 23544662.

5. Gold LS, Yeung K, Smith N, Allen-Ramey FC, Nathan RA, Sullivan SD. Asthma control, cost and race: results from a national survey. J Asthma. 2013;50(7):783-90. Epub 2013/05/04. doi: 10.3109/02770903.2013.795589. PubMed PMID: 23638955.

6. American Lung Association. Luchando porel aire: The burden of asthma among hispanics. New York: 2011 Contract No.: 8/2.

7. Hunninghake GM, Weiss ST, Celedon JC. Asthma in Hispanics. Am J Respir Crit Care Med. 2006;173(2):143-163

8. Wright K, Newman-Giger J. California's young Latino children with asthma: disparities in health care access and utilization of health care services. Lat Health Care Int 2010;8(3):154-164

9. Thakur N, Oh SS, Nguyen EA, Martin M, Roth LA, Galanter J, et al. Socioeconomic status and childhood asthma in urban minority youths. The GALA II and SAGE II studies. Am J Respir Crit Care Med. 2013;188(10):1202-9. Epub 2013/09/21. doi: 10.1164/rccm.201306-1016OC. PubMed PMID: 24050698; PubMed Central PMCID: PMCPmc3863734. 
10. Evans-Agnew RA. Asthma management: An ecosocial framework for disparity research. J Health Disparity Res Prac. 2011;5(1):19. doi: 10.1016/j.envres.2006.05.007. 11. Martin MA, Thomas AM, Mosnaim G, Greve M, Swider SM, Rothschild SK. Home asthma triggers: barriers to asthma control in Chicago Puerto Rican children. J Health Care Poor Underserved. 2013;24(2):813-27. Epub 2013/06/04. doi: 10.1353/hpu.2013.0073. PubMed PMID: 23728047.

12. Martinez IL, Carter-Pokras O, Brown PB. Addressing the Challenges of Latino Health Research: Participatory Approaches in an Emergent Urban Community. J Nat Medical Assoc. 2009;101(9):908-14. doi: https://doi.org/10.1353/hpu.2006.0129.

13. McNally E, Blazina I, Farquhar SA. Community-Based Approaches to Reduce Toxins in Housing: Lessons Learned From Working with Diverse Communities. Environ Justice. 2010;3(3):85-93. doi: 10.1089/env.2009.0041.

14. Kueny A, Berg J, Chowdhury Y, Anderson N. Poquito a poquito: how Latino families with children who have asthma make changes in their home. J Pediatr Health Care. 2013;27(1):e1-11. Epub 2012/12/15. doi: 10.1016/j.pedhc.2011.02.007. PubMed PMID: 23237616.

15. Martinez IL, Carter-Pokras O. Assessing Health Concerns and Barriers in a Heterogeneous Latino Community. J Health Care Poor Underserved. 2006;17(4):899909. doi: https://doi.org/10.1353/hpu.2006.0129.

16. Environmental Working Group. Announcing EWG's Updated Guide to Healthy Cleaning Washington, DC: Environmental Working Group; 2016. Available from: https://www.ewg.org/guides/cleaners/content/spring_2016_update - .W6EDj1JReYU. 17. Fisher TL, Burnet DL, Huang ES, Chin MH, Cagney KA. Cultural leverage: interventions using culture to narrow racial disparities in health care. Med Care Res Rev. 2007;64(5):243S-282S

18. Koinis-Mitchell D, McQuaid EL, Kopel SJ, Esteban CA, Ortega AN, Seifer R, et al. Cultural-related, contextual, and asthma-specific risks associated with asthma morbidity in urban children. J Clin Psychol Med Settings. 2010;17(1):38-48. Epub 2010/02/17. doi: 10.1007/s10880-009-9178-3 [doi]. PubMed PMID: 20157798.

19. Tapp H, White L, Steuerwald M, Dulin M. Use of community-based participatory research in primary care to improve healthcare outcomes and disparities in care. J Comp 
Eff Res. 2013;2(4):405-19. Epub 2013/11/19. doi: 10.2217/cer.13.45. PubMed PMID: 24236682; PubMed Central PMCID: PMCPmc4042315.

20. Postma JM, Evans-Agnew RA, Capouya J. Mexican-American caregivers' perceptions about asthma management: a photovoice study. J Asthma. 2015;52(6):593-9. 21. Evans-Agnew RA, Postma J, Sledd L. "Mi niño con asma": Hispanic/Latina mothers, environmental justice, and photovoice at the front lines of the asthma epidemic. J Health Disparity Res Prac. 2016;9(1):Article 7.

22. Evans-Agnew RA, Postma JM, Ochoa Camacho A, Hershberg R, Trujillo E, Tinajera M. Development and pilot testing of a bilingual environmental health assessment tool to promote asthma-friendly childcares. Prog Community Health Partnersh. 2018;12(1):35-44. doi: 10.1353/cpr.2018.0004.

23. Wang C, Burris MA. Photovoice: concept, methodology, and use for participatory needs assessment. Health Educ Behav. 1997;24(3):369-87. Epub 1997/06/01. doi: 10.1177/109019819702400309. PubMed PMID: 9158980.

24. Postma JM, Evans-Agnew R, Capouya J. Mexican-American caregivers' perceptions about asthma management: a photovoice study. J Asthma. 2015;52(6):593-9. Epub 2014/12/30. doi: 10.3109/02770903.2014.996651. PubMed PMID: 25539397.

25. Israel BA, Krieger J, Vlahov D, Ciske S, Foley M, Fortin P, et al. Challenges and facilitating factors in sustaining community-based participatory research partnerships: lessons learned from the Detroit, New York City and Seattle Urban Research Centers. J Urban Health. 2006;83(6):1022-40. Epub 2006/12/02. doi: 10.1007/s11524-006-9110-1 [doi]. PubMed PMID: 17139552.

26. Catalani C, Minkler M. Photovoice: A Review of the Literature in Health and Public Health. Health Educ Behav. 2010;37(3):424-51. doi: 10.1177/1090198109342084. 27. Strack RW, Lovelace KA, Jordan TD, Holmes AP. Framing Photovoice Using a Social-Ecological Logic Model as a Guide. Health Promot Pract. 2010;11(5):629-36. doi: $10.1177 / 1524839909355519$.

28. Wang CC, Burris MA. Photovoice: Concept, methodology, and use for participatory needs assessment. Health Educ Behav. 1997;24(3):369-87. doi: 10.1177/109019819702400309. 
29. Bandura A. Social cognitive theory and exercise of control over HIV infection. In: DiClemente RJ, Peterson JL, editors. Preventing AIDS: theories and methods of behavioral interventions. New York: Plenium Press; 1994. p. 25-59.

30. Local Hazardous Waste Program in King County. Limpiar con precaucion Seattle, WA2016. Available from: http://www.hazwastehelp.org/translations/spanish.aspx.

31. Pediatrics Northwest. Cómo controlar el asma de su hijo. In: Pediatrics Northwest, editor. Tacoma, WA; 2016.

32. Northwest Clean Air Agency. Ataque el asma en su hogar: Un manera practica de prevenir y controlar lo que puede llegar a "desencadenar" el asma. In: Blake D, editor.: Vid-smith digital video production; 2014. p. 28:03.

33. Nebeker C, Elder J, Talavera G, Coleman K, Kalichman M, McNicholas LJ, et al. Project TRES (Training in Research Ethics and Standards). San Diego, CA: San Diego State University; 2009. Available from: http://interwork.sdsu.edu/capri/docs/TRES_SelfstudyGuide.pdf.

34. Burns N, Grove S. The Practice of Nursing Research Philadelphia: W.B. Saunders; 2001.

35. Jones JA, Wahlgren DR, Meltzer SB, Meltzer EO, Clark NM, Hovell MF.

Increasing asthma knowledge and changing home environments for Latino families with asthmatic children. Patient Educ Couns. 2001;42(1):67-79. doi:

https://doi.org/10.1016/S0738-3991(00)00102-6.

36. Trueblood AB, Rincon R, Perales R, Hollingsworth R, Miller C, McDonald TJ, et al. A Pilot Study of Changes in Environmental Knowledge and Behaviors among Head Start Employees and Parents Following Environmental Health Training in Webb County, TX. J Immigr Minor Health. 2016;18(1):135-42. Epub 2014/12/30. doi: 10.1007/s10903014-0150-4. PubMed PMID: 25538003.

37. Washington State Department of Health. Washington State Health Assessment. Olympia, WA: Washington State Department of Health, 2018.

38. Baker B, Rytina N. Estimates of the Unauthorized Immigrant Population Residing in the United States: January 2012. Department of Homeland Security, 2013. 
39. Ennis SR, Rios-Vargas M, Albert NG. The Hispanic Population: 2010.

Washington, DC: U.S. Dept. of Commerce, Economics and Statistics Administration, 2011 C2010BR-04.

40. Humes KR, Jones NA, Ramirez RR. Overview of Race and Hispanic Origin: 2010. Washington, DC: U.S. Dept. of Commerce, Economics and Statistics Administration, 2011.

41. Cené CW, Haymore LB, Enga Z, Sallah SH, Ritchwood T, Wynn M, et al. Data Collection and Management in Community Engaged Research: Lessons Learned From Two Community-Based Participatory Research Partnerships. Prog Community Health Partnersh. 2015;9(3):413-22. Epub 2015/11/10. doi: 10.1353/cpr.2015.0057. PubMed PMID: 26548793.

42. Formea CM, Mohamed AA, Hassan A, Osman A, Weis JA, Sia IG, et al. Lessons learned: cultural and linguistic enhancement of surveys through community-based participatory research. Prog Community Health Partnersh. 2014;8(3):331-6. Epub 2014/12/02. doi: 10.1353/cpr.2014.0037. PubMed PMID: 25435559; PubMed Central PMCID: PMCPMC4251552.

43. Garcia CM, Gilchrist L, Campesino C, Raymond N, Naughton S, de Patino JG. Using community-based participatory research to develop a bilingual mental health survey for Latinos. Prog Community Health Partnersh. 2008;2(2):105-20. Epub 2008/01/01. doi: 10.1353/cpr.0.0011. PubMed PMID: 20208244; PubMed Central PMCID: PMCPMC3276245.

44. Grisay A. Translation procedures in OECD/PISA 2000 international assessment. Language Testing. 2003;20(2):225-40.

45. Falb K, Tanner S, Asghar K, Souidi S, Mierzwa S, Assazenew A, et al. Implementation of Audio-Computer Assisted Self-Interview (ACASI) among adolescent girls in humanitarian settings: feasibility, acceptability, and lessons learned. Confl Health. 2017;10(1):32. doi: 10.1186/s13031-016-0098-1.

46. Thompson M, Espinoza B, Chavez M, Trujillo E, Ochoa Camacho A, Alonso S, et al. Mujeres Latinas Apoyando la Communidad 2017. Available from: from:https://www.youtube.com/playlist?list=PL-r-Ht1OarqCE_PiwivNnsE6GVUqjZ-Fn. 
47. Oneal GA, Postma J, Odom-Maryon T, Butterfield P. Retest of a Principal Components Analysis of Two Household Environmental Risk Instruments. Res Nurs Health. 2016;39(4):277-85. Epub 2016/05/27. doi: 10.1002/nur.21730. PubMed PMID: 27227487.

48. Krieger J. Home visits for asthma: we cannot afford to wait any longer. Arch Pediatr Adolesc Med. 2009;163(3):279-81. Epub 2009/03/04. doi: 10.1001/archpediatrics.2008.279. PubMed PMID: 19255400.

49. American Lung Association. Medicaid Coverage of Asthma Self-Management Education: A Ten-State Analysis of Services, Providers and Settings. Joint Statement. Washington, DC: American Lung Association, 2017 5/13/2013. Report No.

50. Reddel HK, Taylor DR, Bateman ED, Boulet L-P, Boushey HA, Busse WW, et al. An official American Thoracic Society/European Respiratory Society statement: Asthma control and exacerbations: Standardizing endpoints for clinical asthma trials and clinical practice. Am J Respir Crit Care Med. 2009;180(1):59-99. doi:

10.1164/rccm.200801-060ST.

51. Jackson DJ, Hartert TV, Martinez FD, Weiss ST, Fahy JV. Asthma: NHLBI Workshop on the Primary Prevention of Chronic Lung Diseases. Ann American Thorac Soc. 2014;11 Suppl 3:S139-45. Epub 2014/04/24. doi: 10.1513/AnnalsATS.201312448LD. PubMed PMID: 24754822.

52. Martinez FD. The origins of asthma and chronic obstructive pulmonary disease in early life. Proc Am Thorac Soc. 2009;6(3):272-7. Epub 2009/04/24. doi:

10.1513/pats.200808-092RM. PubMed PMID: 19387029; PubMed Central PMCID: PMC2677402.

53. Rosser FJ, Forno E, Cooper PJ, Celedon JC. Asthma in Hispanics. An 8-year update. Am J Respir Crit Care Med. 2014;189(11):1316-27. Epub 2014/06/03. doi: 10.1164/rccm.201401-0186PP. PubMed PMID: 24881937; PubMed Central PMCID: PMCPmc4098086.

54. Buki LP, Salazar SI, Pitton VO. Design Elements for the Development of Cancer Education Print Materials for a Latina/o Audience. Health Promot Pract. 2008;10(4):56472. doi: $10.1177 / 1524839908320359$. 
55. De Lange N, Mitchell C. Community Health Workers Working the Digital Archive: A Case for Looking at Participatory Archiving in Studying Stigma in the Context of HIV and AIDS. Sociol Res Online. 2012;17(1):1-16. doi: 10.5153/sro.2591. 